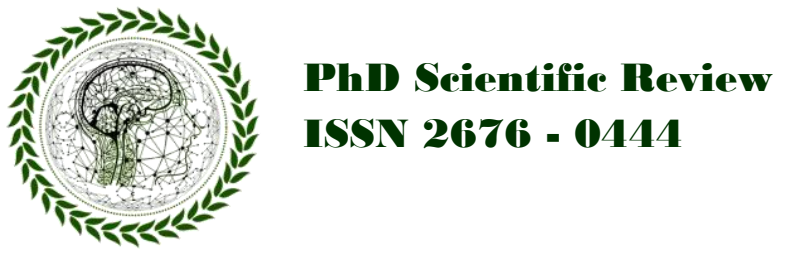

Artigo submetido em: 11/06/2021

Artigo aceito em: 14/06/2021

Artigo publicado em: 24/06/2021

\title{
ENSINO RELIGIOSO ESCOLAR: UMA PRÁTICA NA EDUCAÇÃO BRASILEIRA
}

\author{
MARCUS ANTÔNIO SANTIAGO ${ }^{1}$
}

\section{RESUMO}

A construção histórica do Ensino Religioso Escolar nos seus primórdios foi muito tumultuada. A confusão entre Ensino Religioso, Ensino de Religião ou Catequese era forte no passado e ainda perdura em nossos dias, tanto na teoria como na prática. Daí muita contestação sobre essa tão importante disciplina escolar. No entanto, ele tem o seu itinerário e continua percorrendo caminhos tortuosos e complexos, a fim de legitimar a sua identidade e o porquê de estar na grade curricular até nos dias de hoje. É necessária uma convicção: O Ensino Religioso não é um ensino qualquer, vago, impreciso. Ele tem a sua história, o seu conteúdo específico, a sua metodologia e os elementos que o configuram como área de conhecimento nos termos da Resolução CNE/CEB Nº. 7/2010, que visa à formação integral do educando e sua obrigatoriedade na matriz curricular do Ensino Fundamental. É preciso que tenhamos bem claro o que seja um Estado Laico para compreender melhor as suas obrigações, pois, mesmo sendo laico, o Estado deve assegurar a todos os educandos o direito de receber uma formação integral. Inclusive a formação religiosa desejada, visando "o pleno desenvolvimento da pessoa" (Art. 5 da Constituição Federal 1988). No Ensino Fundamental, o Ensino Religioso oportuniza que temas que envolvam o Fenômeno Religioso e a formação integral do ser humano sejam abordados com criticidade, cientificidade num contexto que haja partilha, diálogo, compreensão e superação de preconceitos advindos de questões etnocêntricas, religiosas, culturais ou de gênero. A proposta deste é rememorar a historicidade do Ensino Religioso discutido ao longo da educação no país dentro dos aspectos históricos e constitucionais, possibilitando uma compreensão em nível nacional das principais motivações que levaram grupos, associações, docentes e pesquisadores a não medir esforços para que essa disciplina fosse regulamentada e incluída na constituição maior do país (CF/1988).

Palavras-chave: Ensino Religioso. Constituições Federais. História da Educação. Laicidade.

\begin{abstract}
The historical construction of School Religious Education in its beginnings was very tumultuous. The confusion between Religious Education, Religious Education or Catechesis was strong in the past and still lingers today, both in theory and in practice. Hence a lot of contention about this very important school discipline. However, he has his itinerary and continues to follow tortuous and complex paths, in order to legitimize his identity and why he is on the curriculum even today. A conviction is necessary: Religious Education is not just any vague, imprecise teaching. It has its history, its specific content, its methodology and the elements that configure it as a knowledge area under the terms of Resolution CNE / CEB No. 7/2010, which aims at the integral formation of the student and its obligation

${ }_{1}^{1}$ Professor na rede pública estadual de ensino. Graduado em Filosofia, Pedagogia, Teologia, Educação Física. Pósgraduado em Gestão Escolar, Ciências da Religião, Educação Empreendedora. Especialista em educação básica/supervisor pedagógico.msantibaniz@gmail.com
\end{abstract}


in the curricular matrix of Elementary Education. We need to be very clear about what a Secular State is in order to better understand its obligations, because, even though it is secular, the State must ensure that all students have the right to receive comprehensive training. Including the desired religious formation, aiming at "the full development of the person" (Art. 5 of the Federal Constitution 1988). In Elementary Education, Religious Education provides opportunities for topics involving the Religious Phenomenon and the integral formation of the human being to be approached with criticality, scientificity in a context where there is sharing, dialogue, understanding and overcoming prejudices arising from ethnocentric, religious, cultural or of gender. The purpose of this is to recall the historicity of Religious Education discussed throughout education in the country within the historical and constitutional aspects, enabling an understanding at the national level of the main motivations that led groups, associations, teachers and researchers to measure their efforts so that this discipline regulated and included in the country's largest constitution (CF / 1988).

Keywords: Religious Education. Federal Constitutions. History of Education. Secularity.

\section{INTRODUÇÃO}

A História do Ensino Religioso na educação brasileira nasceu a partir de aspectos religiosos que se vincularam ao ensino através da aliança entre Estado e Igreja. As formas de governo, ao longo dos tempos, foram ganhando dimensões políticas e ideológicas durante a sua trajetória para que o Ensino Religioso pudesse ser garantido na escola pública e conquistasse seu espaço como área do conhecimento, foi preciso que houvesse muitas reflexões e estudo de documentos normativos, a fim de que esse continuasse na educação básica e ganhasse nova concepção na sua identidade curricular e na prática pedagógica.

Através dos recortes historiográficos, o presente trabalho visa refletir e alinhavar a discussão de toda a trajetória do Ensino Religioso na educação brasileira, através do itinerário histórico e cultural dentro dos principais períodos da história da educação e da discussão entre grupos que eram contra ou a favor da permanência dessa área do conhecimento na educação, justamente porque a disciplina versava sobre ideologias e políticas entre Estado e Igreja.

Ao longo da trajetória do Ensino Religioso podemos observar que foi um desafio muito grande, porque muitos aplicavam os conhecimentos voltados para uma única Teologia e numa determinada época, acrescida da ideologia da religião cristã e anseios advindos de governos, até a publicação do Decreto N. 119-A, de 07 de janeiro de 1890. Mesmo assim foi visível observar que depois da publicação do referido decreto, no qual desvinculava a aliança entre o Estado e a Igreja, o Ensino Religioso ainda continuava de forma proselitista. 
Atualmente o Ensino Religioso, como área de conhecimento, deve ser sempre discutido no seu contexto histórico e sociocultural, através de pesquisa, reflexão, dentro da proposta das Ciências da Religião estabelecendo o diálogo e articulando seu campo de estudo com áreas afins, o que pode contribuir para sua identidade acadêmica, seja na educação básica ou no ensino superior, onde tem sido objeto de estudo e pesquisa.

\title{
2 DESENVOLVIMENTO
}

\subsection{O Ensino Religioso no período colonial}

Segundo, ORDONEZ e QUEVEDO (pág. 98, S.d):

\begin{abstract}
“A Bula Papal de Alexandre VI, "Inter Coetera”, confirmava juntamente com o Tratado de Tordesilhas a legitimação e ocupação das terras. Com as conquistas de terras pela Coroa Portuguesa, formava-se nos primeiros anos do Brasil a colônia, que representava a sociedade da elite portuguesa, com características próprias, visando somente às relações socioeconômicas e de interesses da classe. A aquisição de novas terras pela coroa também constituía conquista religiosa no sentido de difundir o catolicismo".
\end{abstract}

Era desejo profundo de a Igreja levar a fé cristã a todas as partes da terra, mas, com as imposições do Estado, era inviável levar essa missão a cabo. Todavia as perseguições não vinham somente dos governantes, mas também da linha tradicional dentro do próprio clero.

A partir do século 16, houve grande expansão da colonização das Américas, surgindo novos impérios com objetivo de conquistar e explorar novas terras. Esse período se caracterizou pela colonização e evangelização do Brasil. Os novos impérios estavam diretamente ligados à religião dominante. A aliança Igreja-Estado continuava com seus ditames.

$\mathrm{Na}$ época do padroado, eram vários os interesses do Estado. Desde a Cristandade, se houvesse combate com a política do Estado, correr-se-ia o risco de estar indo também contra a Igreja, por ambos estarem entrelaçados. O direito de padroado dos reis de Portugal só poderia ser entendido dentro de todo o contexto da história medieval. O padroado era a forma pela qual o governo de Portugal exercia suas funções de proteção sobre a Igreja Católica, pelo fato dessa ser a religião oficial e a única permitida.

Por meio de bulas e outros documentos papais os direitos sobre novas terras eram dados aos portugueses para que a Igreja buscasse a conversão de pagãos e infiéis. Quanto mais os 
monarcas tinham seu poder fortalecido, mais exigiam os privilégios da Santa Sé, em troca do apoio dado à política eclesiástica.

Contudo, é importante lembrar que o padroado nasceu para favorecer a catequese e a implantação da Igreja nas novas terras, mas na realidade o padroado degenerou-se num sistema opressivo, perdendo o seu significado religioso. Limitou a ação evangelizadora da Igreja e as iniciativas pastorais, acabou com o entusiasmo dos religiosos e reduziu a criatividade dos obreiros no âmbito missionário.

Os portugueses chegaram, desembarcaram numa praia onde hoje é a Bahia e logo tomaram posse da terra para o rei de Portugal. Como sinal desta posse, fincou no local um marco de pedra, que traziam os sinais do rei, e a cruz. A terra agora, conforme entendiam os portugueses, pertencia ao rei de Portugal. Nas embarcações traziam capelães. Uma parte da tomada de posse da nova terra foi a celebração da primeira missa nas terras do Brasil, pelo Frei Henrique Coimbra. A essa terra os portugueses cristãos deram o nome de "Terra de Santa Cruz".

Depois de um longo percurso, ainda nesse século, nos países europeus desencadeava a Reforma Religiosa, onde diversos fatos ocorriam e atingiam as colônias que estavam em processo de cristianização. A Reforma Protestante (1517), chefiada por Martinho Lutero que desejava uma renovação da Igreja, fez com que surgissem novas igrejas cristãs com diferentes doutrinas. A elite, preocupada com essa visão proposta por Lutero, começou o movimento da Contra-Reforma, que resultou na divisão entre católicos e protestantes. Com efeito, a Igreja Católica não contava mais com o seu monopólio religioso, pois, a partir da reforma protestante, foram surgindo diversos grupos cristãos.

Com a colonização do Brasil, o cristianismo, como religião predominante, alicerçava suas bases católicas nos primeiros tempos da nova jurisdição que se formava. Em 1551, foi criado o primeiro Bispado do Brasil - Diocese de São Salvador da Bahia - cujo primeiro bispo foi Dom Pero Fernandes Sardinha.

Em 27 de março de 1549, seis sacerdotes da Companhia de Jesus - Jesuítas - liderados pelo Padre Manoel da Nóbrega desembarcaram no local onde se ergueria a cidade de Salvador, na Bahia, acompanhados do primeiro governador-geral, Tomé de Souza. Tempos depois chegaram outros sacerdotes para auxiliar no apostolado missionário e educacional.

Os Jesuítas eram membros de uma nova ordem religiosa fundada por Santo Inácio de Loyola. Eram cheios de amor a Jesus e ao evangelho e desejavam evangelizar e salvar as almas 
dos índios através da catequese. Portanto, eles vinham realmente com intenção missionária compreendida à maneira daquela época. No entanto, havia diferença no modo de ver a missão por parte dos Jesuítas e pelos colonizadores leigos. Os Jesuítas vieram com o objetivo de evangelizar e salvar almas, e os colonizadores queriam, antes de tudo, progredir em seus negócios, explorar a mão de obra dos índios através do trabalho escravo.

Entretanto, a educação no Brasil inicialmente se constituiu de forma subsidiária e pouco especializada, ocupada por religiosos de diversas ordens religiosas ou mesmo por leigos. Afirma Nóvoa:

A gênese da profissão de professor tem lugar no seio de algumas congregações religiosas, que transformaram em verdadeiras congregações docentes. Ao longo dos séculos XVII e XVIII, os jesuítas e os oratorianos, por exemplo, foram progressivamente configurando um corpo de saberes e de técnicas e um conjunto de normas específicos da profissão docente. (1991, p.12)

Assim, as congregações e ordens religiosas aos poucos vão habitando a Colônia e tornando-se os primeiros educadores. Fundaram vários Colégios, onde se ministravam as aulas e também se prestavam serviços sociais à população. O Colégio da Bahia foi um dos mais importantes da Colônia e funcionou nos primeiros tempos como espécie de seminário para formação do clero diocesano e dos próprios Jesuítas, aceitando também os leigos.

Mais tarde, a Igreja de Roma se preparava para o Concílio de Trento (1545-1563), tendo em vista o estudo de diversas questões dogmáticas e históricas, questionadas pelos protestantes. Ao término dessa etapa na vida da Igreja, a mesma se fortalecia e se estruturava nos moldes tridentinos, acentuando, assim, o seu caráter institucional dentro do Regime de Padroado.

No ano de 1581, realizaram-se as missões através da ordem religiosa dos Beneditinos, com fim de colaborar no apostolado missionário e cumprir os ideais da Igreja Católica. Posterior a esse período, outras ordens religiosas, foram vindo para o Brasil, como os franciscanos, por exemplo. Com a missão de catequizar os índios e negros, a Igreja Católica no Brasil, através de seus sacerdotes, era responsável pelo ensino da religião oficial, conhecimentos doutrinários e pela transmissão da cultura metropolitana.

Os missionários Jesuítas, Benditinos e outras ordens religiosas, embora tivessem a missão primordial da evangelização, se preocupavam também com a instrução de várias técnicas de plantio e desenvolvimento de atividades agrícolas. Criaram os aldeamentos para os índios, 
procurando libertá-los através da perspectiva e da catequese católica. Os Inacianos foram, simultaneamente, missionários, educadores e organizadores da incipiente vida social e eclesiástica da Colônia, inspirados nos altos ideais do Evangelho: liberdade, justiça e fraternidade.

Nos idos de 1707, período esse marcado pelas características da cristandade colonial, foi aprovado pelo Sínodo Arquidiocesano um documento que trazia considerações de como seria a “educação religiosa" para a população. O mesmo foi intitulado "Constituições Primeiras do Arcebispado da Bahia", e obedecia aos padrões e formalidades impostos pelo Concílio de Trento. O referido documento legitimava a obrigação dos senhores de darem formação religiosa aos escravos. Aos vigários, também a incumbência de ensinar a doutrina cristã aos escravos e aos meninos. Desse modo, esse tipo de ensino religioso, mesmo tendo ainda categoria de "matéria", fazia parte do ensino para orientar no aprendizado da leitura e escrita, associado com o ensino das letras e da matemática. Desse modo, simultaneamente ocorria a alfabetização e doutrinação por meio do estudo das Sagradas Escrituras.

Um ano depois da vinda dos Jesuítas para o Brasil (1550), fundaram o Colégio de São Paulo e outras escolas pela Colônia, inserindo o Ensino Religioso ou Aulas de Religião na educação brasileira. O ensino ministrado pelos sacerdotes da Companhia de Jesus contava com o apoio e incentivo da Coroa Portuguesa. Nos seus próprios moldes, dava a educação pública de forma "religiosa", com subvenção advinda da Coroa, ensinando ainda a cultura portuguesa e os princípios do catolicismo.

Com o passar dos tempos, o modelo vigente de ensino não mais atendia aos requisitos da época. O Estado tinha objetivos maiores: integrar e buscar a modernização como as outras nações europeias. Daí aconteceu a reforma pombalina que contrastava com o domínio das ideias religiosas, pois buscava uma ampliação dos horizontes. Esse período foi considerado também um marco na história da educação no Brasil que se estendeu até 1759, quando a Colônia passou por diversas transformações com a vinda do Marquês de Pombal, trazendo ideias iluministas. A chegada do pensamento Iluminista e a pressão política do Marquês de Pombal, que tinha aversão ao cristianismo, culminaram com a expulsão dos Jesuítas de suas Colônias em Portugal, fazendo com que novas ideias fossem incorporadas à educação, principalmente aos moldes de outros países, transformando o Estado, que era considerado "sacro", num Estado com princípios "leigo". 
Com o fechamento dos Colégios Jesuítas, pelo Alvará de 28 de junho de 1759, as "aulas régias" que já existiam continuaram a ser mantidas pela Coroa sendo a primeira experiência do "ensino público", porém com estrutura fragmentada pela falta de recursos por parte do Estado. $\mathrm{Na}$ verdade elas eram próprias de outras modalidades de ensino e que passaram a ser hegemônicas quando da expulsão da Companhia de Jesus, por falta absoluta de outra rede de ensino focada na escolástica e erudição clássica. Nesse período deu-se início aos primeiros projetos com objetivo de se criar uma escola pública estatal.

\subsection{O Ensino Religioso no período imperial}

Considerando que Igreja e Estado são reconhecidos como instituições distintas por sua natureza, a Constituição da República dos Estados Unidos do Brasil de 1891, no parágrafo 6º do artigo 72 diz: "Será leigo o ensino ministrado nos estabelecimentos públicos". Esse dispositivo inicialmente foi o gerador dos debates sobre a laicidade do ensino contra toda forma de proselitismo e confessionalismo religioso no espaço escolar. Nessa concepção, o ensino deveria ter características livres de qualquer influência religiosa.

A Laicidade que já nos referimos é aquela que dispõe de maneira institucional e faz com que, nas sociedades, seja democrática a relação entre o cidadão e o Estado. Inicialmente, a problemática do termo laicidade vinha constituindo uma vertente de pensamento onde se fazia a distinção entre a sociedade civil de aspectos religiosos com ênfase numa visão livre de qualquer convicção religiosa. No entanto, o termo se desdobrou gerando outras ideias que levassem a liberdade de pensamento e suas múltiplas dimensões, bem como a autonomia do Estado frente à sua estrutura, organização política e administrativa.

O Ensino Religioso, em tempos remotos, direcionava seu conteúdo a aspectos religiosos de grupos específicos ou de orientação religiosa e doutrinária, dificultando a prática ecumênica e dispersando o direito à liberdade religiosa. Mas havia pessoas que concebiam ideias de que, para se garantir o Ensino Religioso no espaço escolar, o elemento eclesial seria fundamental, mesmo que estivesse aos auspícios de uma determinada religião. Sendo assim, haveria um grande transtorno, pois os alunos que não optassem por assistir aulas dessa disciplina ficariam de fora, e a escola não dispunha de atividades para suprir o horário vago e nem preparada para enfrentar esse tipo de desafio. 
Diante das contradições sobre o Ensino Religioso sejam a partir de modelos estrangeiros trazidos para a organização do sistema educacional a preocupação era assegurar a liberdade religiosa dentro de uma visão hermenêutica e filosófica de pensamento nas diversas manifestações existentes nos grupos heterogêneos. Porém, com o caminhar do Estado republicano, autoridades eclesiásticas procuravam a cada dia legitimar o Ensino Religioso através de seus congressos católicos, abaixo-assinados e cartas reivindicatórias propondo às lideranças governamentais a organização da legislação do tema.

Enquanto isso, o tema em questão deixava claro que na vida escolar poder-se-iam surgir inúmeras ocasiões que orientariam os alunos a conceber pensamento religioso, voltada aos deveres para com Deus e a uma vivência religiosa, de determinada religião. Contudo, ainda existia uma visão isolada da diversidade religiosa, por ser o Catolicismo no Brasil predominante e praticado por muitos no país. Assim o Ensino Religioso ministrado dava margens a sobrepor a Catequese Católica na sala de aula trazendo para a escola dogmas, orações e preceitos de uma religião.

O Decreto de 1891, nos seus dispositivos que tratam do ensino leigo, não foi obstáculo para alguns estabelecimentos de ensino público, continuarem com sua metodologia embasada na Catequese ou continuação do Catecismo. De acordo com leis vigentes de cada período da história da educação, o Ensino Religioso era facultativo e, em horários fora da carga curricular, sendo ministrado por pessoas ligadas a uma determinada crença religiosa. Fato que para lecionar tal conhecimento o candidato deveria ser credenciado por autoridade religiosa através de entidades ou Conselhos de Ensino Religioso. Todavia, esses tinham a autonomia para ministrar o conteúdo de acordo com sua a opção religiosa ou através de um programa específico que elencasse os objetivos da opção religiosa.

Daí gerava o entendimento que essa área de conhecimento dentro do espaço escolar era como se fosse uma continuidade da catequese escolar, aula de religião, religião na escola ou mesmo o nome "Ensino Religioso" carregado de preconceitos, pois a ênfase que caracterizava o ensino tinha como herança a Religião Católica. Ainda havia também as escolas de confissões religiosas que ministravam o Ensino Religioso de acordo com a opção religiosa do alunado. Por exemplo, em colégios, institutos e escolas de confissão católica o Ensino Religioso era ministrado em caráter "ético-religioso" e muitos pais ainda matriculavam seus filhos para serem preparados 
para admissão nos sacramentos da Eucaristia e Crisma. Já as de confissões protestantes ou evangélicas dedicavam a disciplina para conteúdos também confessionais da própria doutrina.

\subsection{O Ensino Religioso atualmente}

No contexto atual, sobretudo, na rede pública, o Ensino Religioso é caracterizado de maneira política, democrática, livre, que a sociedade civil lida com relação entre o indivíduo e o Estado. Desse modo, alguns membros da sociedade civil se julgam ter o livre arbítrio de caminhar independentemente de crenças e opções religiosas dos diversos grupos, porém garantindo a liberdade de pensamento, consciência, convicção sócio-cultural e religiosa e chegam a afirmar que o espaço escolar deva ser um lugar de neutralidade de crenças e livres de aspectos religiosos e filosóficos de qualquer instituição religiosa ou afim.

Os novos tempos propõem à sociedade abertura e diálogo para o diferente, incluindo e somando outros valores. Certamente, esse fato justifica a preocupação de membros estarem envolvidos em diversos setores educacionais e empenhados na organização do ensino no país, elaborando parâmetros, projetos pedagógicos em nível nacional a fim de atingir a todos igualmente.

Anos mais tarde, foram criados projetos, leis, decretos, em muitos Estados do Brasil que, aos poucos, apontavam caminhos para que o Ensino Religioso se distinguisse da catequese católica ou de qualquer outra confissão religiosa. Uma das conquistas foi a criação do FONAPER - Fórum Nacional Permanente de Ensino Religioso, em 26 de setembro de 1995, cuja aprovação se deu em assembleia do fórum no ano de 1996. O FONAPER é uma sociedade civil sem vínculo político-partidário, confessional e sindical, que tem como objetivo ser uma representação nacional de todos os trâmites do Ensino Religioso enquanto disciplina escolar; é uma associação composta de professores, pesquisadores e instituições.

Um dos passos importantes do Fórum Nacional Permanente de Ensino Religioso (FONAPER), na época, foi a valorização e busca por um aprimoramento do dispositivo da Lei de Diretrizes e Bases (9.394/96) na disciplina Ensino Religioso, dando novo entendimento ao artigo que trazia em seu contexto distorções históricas que sempre, ao longo da história, abarcou aspectos prolixos de leis anteriores no que se refere ao Ensino Religioso. O caminho percorrido 
foi tomado quando pessoas ligadas à área de ensino, através de entidades constituídas, civis e religiosas, preocupavam-se a lei 9.394/96, no dispositivo referente à disciplina.

O Fórum Nacional Permanente de Ensino Religioso, com o compromisso assumido com a constituição da disciplina, procurou rever o enunciado da referida lei. Conclamou os interessados no assunto para participarem de sessões plenárias, seminários com instituições de ensino superior, mesas redondas no fórum de Conselho Estadual de Educação, reuniões com a Secretaria de Educação Superior de Brasília e demais instituições para organização de debates e elaboração dos Parâmetros Curriculares Nacionais de Ensino Religioso - PCNER (1996), definindo metas e caminhos a serem percorridos desde a elaboração dos conteúdos à admissão e formação de professores para o Ensino Religioso.

Atualmente, os Parâmetros Curriculares Nacionais de Ensino Religioso - PCNER são adotados por algumas Secretarias Estaduais de Educação e Órgãos Municipais de Educação como referência pedagógica. Também pelos futuros professores da área, como material didático para estudo, pesquisa e formação.

Outro questionamento que surgiu, recentemente, a respeito da laicidade do Ensino Religioso foi o da assinatura do Acordo entre a República Federativa do Brasil e a Santa Sé. No dia 13 de novembro de 2008, na cidade do Vaticano, por ocasião da audiência privada do Presidente Luiz Inácio Lula da Silva com Sua Santidade, o Papa Bento XVI, foi assinado um Acordo entre a República Federativa do Brasil e a Santa Sé, relativo ao estatuto jurídico da Igreja Católica no Brasil. Na área da Educação o artigo 11, estabeleceu:

\footnotetext{
“A República Federativa do Brasil, em observância ao direito de liberdade religiosa, da diversidade cultural e da pluralidade confessional do País, respeita a importância do ensino religioso em vista da formação integral da pessoa. $\int 1^{\circ}$. O ensino religioso, católico e de outras confissões religiosas, de matrícula facultativa, constitui disciplina dos horários normais das escolas públicas de ensino fundamental, assegurado o respeito à diversidade cultural religiosa do Brasil, em conformidade com a Constituição e as outras leis vigentes, sem qualquer forma de discriminação."
}

O referido Acordo contrariou membros de associações e grupos que lutam pela laicidade do Ensino Religioso, sobretudo na rede pública. Assim, membros do Supremo Concílio da Igreja Presbiteriana do Brasil redigiram um "Manifesto," discordando, argumentando e justificando a posição a respeito do Acordo firmado entre a República Federativa do Brasil e a Santa Sé. Eis: 
VI. - O termo católico após a expressão "ensino religioso", contido no Acordo, afronta a previsão do $\int 1^{\circ}$ do artigo 210 da Constituição da República, que preceitua: "O ensino religioso, de matrícula facultativa, constituirá disciplina dos horários normais das escolas públicas de ensino fundamental". O Acordo com a Santa Sé consignou no $\int 1^{\circ}$ do artigo 11 que: "O ensino religioso, católico e de outras confissões religiosas, de matrícula facultativa, constitui disciplina dos horários normais das escolas públicas de ensino fundamental...". Trata-se de evidente discriminação religiosa.

No artigo, "O Ensino Religioso no Acordo entre a Santa Sé e Estado Brasileiro", de autoria do teólogo e Bispo de Petrópolis, Dom Filippo Santoro, expõe sua visão acerca da relevância da disciplina na formação integral do ser humano:

"Entre os muitos pontos de grande importância do Acordo estipulado ontem, entre a Santa Sé e o Estado Brasileiro, queremos destacar o reconhecimento do Ensino Religioso seja ele católico, como de outras confissões religiosas nas escolas públicas do ensino fundamental. Esta forma de Ensino que podemos chamar "pluriconfessional" está plenamente em sintonia com quanto previsto pela Constituição Federal, Art. 210, $\int 1^{\circ}$ e pela Lei de Diretrizes e Bases da Educação, Art. 33. O atual Art. 210 da Constituição Federal de 1988 determina: «O ensino religioso, de matrícula facultativa, constituirá disciplina dos horários normais das escolas públicas de ensino fundamental». É inegável que o ensino religioso não deve ser entendido como alusivo a uma "religião genérica", a-confessional, indefinida, já que uma tal 'religião' não existe. Seria pura abstração mental, sem correspondência na realidade da vida e da sociedade humana. E se o Estado quisesse administrar esta forma de ensino genérica, esta sim seria contra a laicidade do próprio Estado porque ele não possui uma religião própria, mas deve respeitar as formas religiosas que se encontram na sociedade. Deve-se sublinhar que esse ensino religioso é sim 'confessional', mas é, ao mesmo tempo, pluralista, enquanto o Estado oferece aos alunos de todos os credos os ensinos religiosos próprios, em conformidade com sua identidade de fé, e é perfeitamente democrático e leigo, porque só será ministrado aos que, livre e facultativamente, o requeiram. A temática do Ensino Religioso é um ponto decisivo desta batalha por uma sociedade feita de vários sujeitos diferentes que convivem e se respeitam". (Revista Passos, 2008, 16)

Os princípios da laicidade requerem que o Estado e as formas de governo não tenham acordo ou orientação de nenhuma confissão religiosa ou filosofia de vida por se tratar dos espaços públicos em questão.

Mas o tema ainda divide opiniões, segundo Claudete Cruz, presidente da Associação dos Professores de Ensino Religioso Católico (ASPERC), no documento "em defesa da formação religiosa dos alunos nas Escolas Municipais do Rio de Janeiro” ela afirma: 


\begin{abstract}
“O Estado brasileiro é Laico e DEMOCRÁTICO. Não é ateu e por isso deve possibilitar, incentivar e promover a diversidade cultural dos grupos de pessoas que o compõem. A Escola não se destina apenas a preparar força de trabalho. Deve preparar os alunos para a vida de que fazem parte, tanto a técnica, como a cultura, o bem-estar material, os valores e a dimensão religiosa. O ensino é para educar, isto é, formar a pessoa, na totalidade das suas dimensões cognitiva, física e também, religiosa. O Ensino Religioso é disciplina escolar, como qualquer outra, que faça parte do currículo escolar, visando a formação integral dos cidadãos e das cidadãs que frequentam a escola, para aí receberem os conhecimentos de que necessitam em todas as áreas, incluindo as relacionadas às indagações do sujeito religioso ou não, dentro ou fora do grupo religioso, ou de instituição religiosa. (...) Os conhecimentos referentes às explicações sobre o sentido da vida, que incluem os conteúdos vinculados ou explicados pelas religiões e suas manifestações diversificadas, são transformados em saber escolar."
\end{abstract}

Todavia, sabemos que o componente curricular de Ensino Religioso é obrigatório na rede pública oficial de ensino e facultativo ao aluno, desse modo o estabelecimento de ensino deve informar os pais ou responsáveis pela opção dessa aula para o seu filho no ato da matrícula. Assim evitará transtornos para os pais que não querem que seus filhos participem dessa aula. Mas por esse conteúdo fazer parte das 800 horas da base curricular nacional o aluno será encaminhado para a realização de outra aula ou projeto pedagógico para cumprir a carga horária.

\title{
3 CONSIDERAÇÕES FINAIS
}

Há algum tempo o Ensino Religioso foi considerado parte integrante da formação básica do cidadão e livre da direção confessional. Isto é obra da Lei 9.394 de 20 de dezembro de 1996, art. 33, reformulado pela lei 9.475 de 22 de Julho de 1997, que diz: “O ensino religioso, de matrícula facultativa, é parte integrante da formação básica do cidadão e constitui disciplina dos horários normais das escolas públicas de ensino fundamental, assegurado o respeito à diversidade cultural religiosa do Brasil, vedadas quaisquer formas de proselitismo".

Muito embora a lei assevere sobre o caráter público, a função social e o respeito à diversidade cultural religiosa, muitas práticas pedagógicas do Ensino Religioso Escolar em sala de aula não sofreram solução de continuidade. Ou seja, o que acontece em sala de aula está muito aquém do que recomenda a lei. Em parte, isto se explica porque ainda um grande número de professores não tem assegurada uma formação adequada à nova lei. Esta realidade está sendo 
enfrentada por instituições (grupos de estudo e pesquisa) interessadas na formação integral do cidadão.

Mas, há outra questão, que geralmente escapa na análise dos problemas que envolvem o Ensino Religioso e que, talvez seja ainda mais importante que a consciência da nova lei: é o lugar que o sagrado - o religioso - ocupa na construção da identidade das pessoas. O sagrado, na cultura ocidental, tende a ser tomado como verdade inquestionável, como critério de certeza absoluta.

O problema, em tese, é o seguinte: o fenômeno religioso é facilmente compreendido e, por este viés, a diversidade é tolerada. Isto é, aceitamos com certa facilidade que o ser humano tem uma dimensão religiosa. Até esta altura, o diálogo flui tranquilamente. Os conflitos começam a aparecer quando tocamos nas ideias sagradas e nos ritos através dos quais nos relacionamos com o transcendente.

Em suma, o Ensino Religioso quer ser um meio onde educandos e educadores possam ter a oportunidade de dialogar e pensar criticamente a vida, a sociedade, o ser humano num todo, respeitando suas aspirações mais profundas dentro de uma visão ética, filosófica, antropológica e cultural, para construção de um mundo melhor, com mais dignidade, justiça, solidariedade e fraternidade.

\section{REFERÊNCIAS}

BRASIL. Lei No. 9.475, de 22 de julho de 1997. Dá nova redação ao Artigo 33 da Lei No. 9.394, de 20 de dezembro de 1996, que estabelece as diretrizes e bases da educação nacional.

Fórum Nacional Permanente do Ensino Religioso. Parâmetros Curriculares Nacionais do Ensino Religioso. $2^{a}$ Edição. Ave Maria: São Paulo, 1997.

Manifesto da Igreja Presbiteriana do Brasil sobre o acordo firmado entre a República Federativa do Brasil e a Santa Sé e a "Lei Geral das Religiões" (Projeto de Lei No. 5.598/2009 e $\quad$ o $\quad$ PLS 160/2009). Disponível em www.ipb.org.br//portal/component/content/article/67-nacionais171. Acesso em: 01/02/2021 
Nota da Associação dos Professores de Ensino Religioso Católico em Defesa da Formação Religiosa dos Alunos nas Escolas Municipais do Rio de Janeiro. Disponível em:

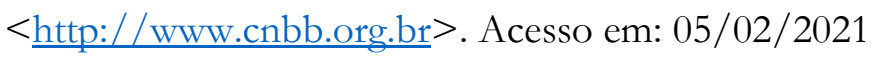

NÓVOA, Antônio. (Org.). Profissão professor. Lisboa-Portugal: Dom Quixote, 1991. p.12

D. Fillipo Santoro. O Ensino Religioso no Acordo entre a Santa Sé e Estado Brasileiro. Revista Passos. No 100, dezembro/2008. p.16. Disponível em:

$<$ http://www.pucsp.br/fecultura/textos/pessoa sociedade/ensino religioso.html $>$. Acesso em: 15/02/2021

ORDONEZ, Marlene e QUEVEDO, Júlio. História Geral. Editora IBEP: São Paulo. S.d. 